\title{
What is the impact of pregnancy and parenthood on studying medicine? Exploring attitudes and experiences of medical students
}

\begin{abstract}
${ }^{1} \mathrm{~K}$ Khadjooi, ${ }^{2} \mathrm{P}$ Scott, ${ }^{3} \mathrm{~L}$ Jones School, York, UK

ABSTRACT Medical students are often faced with stressors such as high work demands, numerous assessments, placements and career choices. Using the results of a questionnaire we examined medical students' attitudes and choices surrounding the impact of pregnancy and parenthood on studying medicine. Many questionnaire respondents $(\mathbf{7 7 . 6 \% )}$ believe that the decision to have a child is influenced by studying medicine; $23 \%$ have delayed becoming a parent and $7.5 \%$ have chosen not to have children. The four most common factors considered to be barriers for parent/pregnant medical students are lack of time, financial difficulties, the stressful and demanding nature of the course and social factors. Almost $90 \%$ of the respondents were not aware of the support available for pregnant students/parents. Specialised, well-publicised and easily accessible support services as well as flexibility in their training programme and clinical placements can ensure full and successful participation of pregnant/parent medical students in learning.
\end{abstract}

${ }^{1}$ Specialist Registrar/Honorary Tutor in Stroke Medicine, Department of Medicine, Scarborough General Hospital, North Yorkshire, UK; ${ }^{2}$ Manager of Learning Resources, Hull York Medical School, York, UK; ${ }^{3}$ Senior Lecturer in Social Policy and Social Work, Hull York Medical

\author{
Correspondence to K Khadjooi, \\ Department of Medicine, \\ Scarborough General Hospital, \\ North Yorkshire YOI 2 6QL, UK
} e-mail kayvan@nhs.net

KEYWORDS Study of medicine, pregnancy, parenthood, medical students

DECLARATION OF INTERESTS No conflicts of interest declared.

\section{INTRODUCTION}

Medical training is demanding and over one-third of medical students suffer from psychological morbidity. ${ }^{1-3}$ A high proportion of this distress is caused by courserelated pressures: workload, fear of falling behind others and exam failure are particular preoccupations for medical students. ${ }^{3}$ Some studies have looked at the impact of pregnancy and parenthood on students and professionals. A survey in the US Army for example showed that although parenthood and pregnancy are compatible with a military career, the potential for individual, family and organisational disruption is high. ${ }^{4}$ An analysis in Sweden demonstrated that due to concerns about the impact of pregnancy on their studies, men and women in higher education are delaying starting a family. ${ }^{5}$ Meet the parents, by the National Union of Students (NUS) ${ }^{6}$ was the first UK-wide report into the experiences of students with children in further and higher education. It identified some of the challenges faced by parent students in undertaking studies: financial pressures, reduced benefits, insufficient childcare funding and the difficulty of getting involved with student life outside the course. In addition, it highlighted the lack of clear or consistent funding entitlement and provision of information about childcare options and financial entitlements for student parents. ${ }^{6}$

There are however very few studies looking at the impact of pregnancy and parenthood on healthcare professionals and most of them have focused on nursing students or postgraduate trainees. The Nursing education barriers identification survey by the Mississippi Office of Nursing Workforce for example indicated that the responsibilities of caring for young children were a major factor contributing to the attrition rates among parent nursing students. ${ }^{7}$ The impact of pregnancy and parenthood on medical students has not been adequately addressed and the purpose of our study was to explore this.

\section{METHODS}

\section{Participants}

We conducted a study of all medical students and new graduates (working as a Foundation Year I doctor) from a medical school in the UK.

\section{Aims}

The aim was to explore students' opinions, choices, experiences and attitudes about pregnancy and parenthood, including the views of those who are not pregnant/parents.

The main questions were:

- How does being or becoming a parent affect their studies?

- What are the barriers or difficulties a parent/ pregnant student might face in pursuing their medical studies?

- How can these barriers be addressed? 
TABLE I The questionnaire results

\begin{tabular}{|c|c|c|c|c|c|}
\hline & Question & Yes & No & Unanswered & Comments \\
\hline \multicolumn{6}{|c|}{ Part I } \\
\hline 1 & $\begin{array}{l}\text { Have you/your partner been pregnant } \\
\text { during the course of study of medicine? }\end{array}$ & $6.9 \%$ & $93.1 \%$ & & \\
\hline 2 & $\begin{array}{l}\text { Are you anticipating having children in } \\
\text { the near future? }\end{array}$ & $21.3 \%$ & $78.2 \%$ & $0.5 \%$ & \\
\hline 3 & $\begin{array}{l}\text { Do you have children (including } \\
\text { stepchildren, adopted children, guardian/ } \\
\text { caretaking responsibility)? }\end{array}$ & $7.5 \%$ & $92 \%$ & $0.5 \%$ & $\begin{array}{l}\text { Number of children ranged from } \\
\text { one to three, the youngest two } \\
\text { weeks old and the eldest I } 4 \\
\text { years old.Three students had } \\
\text { stepchildren and one had an } \\
\text { adopted child. }\end{array}$ \\
\hline 4 & $\begin{array}{l}\text { Have you delayed parenthood because } \\
\text { of study of medicine? }\end{array}$ & $23 \%$ & $77 \%$ & & \\
\hline 5 & $\begin{array}{l}\text { Have you chosen not to have children } \\
\text { because of study of medicine? }\end{array}$ & $7.5 \%$ & $92.5 \%$ & & \\
\hline \multicolumn{6}{|c|}{ Part 2} \\
\hline 1 & $\begin{array}{l}\text { Do you think studying medicine affects } \\
\text { the decision to become a parent? }\end{array}$ & $77.6 \%$ & $20.7 \%$ & $1.7 \%$ & \\
\hline 2 & $\begin{array}{l}\text { What barriers or difficulties do you } \\
\text { think a parent/pregnant medical student } \\
\text { may face? }\end{array}$ & $\mathrm{n} / \mathrm{a}$ & $\mathrm{n} / \mathrm{a}$ & $\mathrm{n} / \mathrm{a}$ & \\
\hline 3 & $\begin{array}{l}\text { Are you aware of the support available } \\
\text { for pregnant/parent students? }\end{array}$ & $9.2 \%$ & $89.1 \%$ & $1.7 \%$ & \\
\hline
\end{tabular}

\section{Main mode of administration}

A self-completion questionnaire (tested in an initial small pilot study) was used.

\section{Recruitment}

We emailed potential participants with information about the study and a link to the questionnaire.A reminder email was sent a few weeks later. The aims of the study were highlighted in an announcement on the medical school's intranet. To maximise the availability of participants we contacted them a few weeks after the start of the term. The questionnaire was available online for four months, from October 2009 to January 2010.

\section{Ethical considerations}

All potential participants were assured that the information obtained would be treated with the strictest confidence. The online questionnaire was designed by the IT department so that each participant could access it only through the use of an individual username and password for the medical school's intranet and no individual could access other participants' questionnaires. All data were anonymised and no individual could be identified by other participants or by the study team.

\section{RESULTS}

Out of a total of 730 people who received the email $(600$ students and I 30 newly qualified doctors), I 74 completed the questionnaire, giving a $24 \%$ response rate. The age range was 18-44 (average age 22.5 ) and $74 \%$ of participants were female. The respondents were almost equally representative of different stages of medical school (year I to 5 ), but only $5.7 \%$ of participants were newly qualified

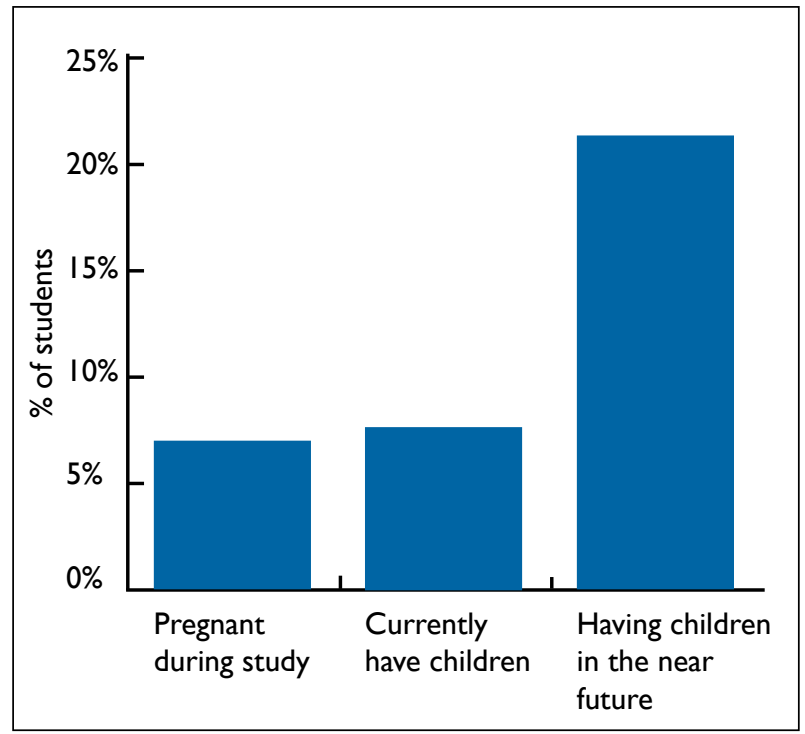

FIGURE I Proportion of students who are pregnant, already a parent or planning to have children in the near future. 
doctors, possibly because after graduation many students no longer use their medical school website and email address. Of the respondents, $23.5 \%$ were married or living with a partner and the proportion of students who were a parent or pregnant are shown in Figure I.The participants were asked eight questions and Table I shows the questionnaire results.

In response to question two (part two), respondents were able to select more than one answer and the following factors were identified as the main barriers or difficulties a parent/pregnant medical student may face (Figure 2).

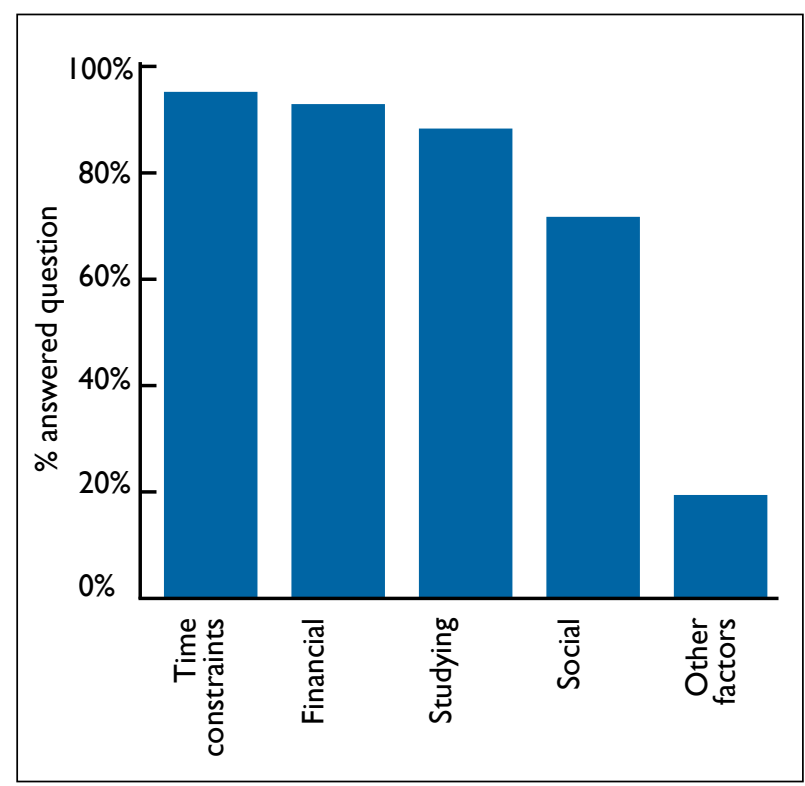

FIGURE 2 Barriers or difficulties a parent/pregnant student may face.

There was a free text section for option number five (other factors) and the following factors were repeatedly highlighted in participants' comments:

- Emotional and psychological aspects: for example stress and anxiety over a child's illness, fear of studies and/or the relationship with the child suffering.

- Career progression: the belief that medicine and studying must be prioritised in order to be successful.

- Geographical factors: moving around between rotations leading to a sense of instability affecting their relationships and parenting.

- Childcare and the welfare of child.

- Women feeling that they have to choose between career and parenthood.

- Balancing academic commitment and family responsibilities.

- Lack of peer support.

- Fear of discrimination when applying for jobs.

\section{DISCUSSION}

In our study, $14.4 \%$ of respondents had children or were pregnant (either the student or their partner). Medical schools are not required to collect information regarding marital status or number of children, so it is therefore not possible to know the exact number of parent medical students.

We found that almost a quarter of participants had delayed becoming a parent because of studying medicine. This delay can also extend to later stages in their career: some wait until after they complete their foundation years and some until after they become a consultant. One student commented:'There is no good point during studying medicine prior to being a consultant where it is easy to take time out to have a family.' An additional $7.5 \%$ of respondents chose not to have children because of studying medicine: 'Friends who were considering doing medicine as a mature student were put off because of wanting to be parents. Friends who were studying medicine put off being parents until later on.' The length of time spent training in medicine is one of the commonly cited factors influencing the decision to delay starting a family: Very long training, you tend to be occupied during the years when most people have children!'

More than three quarters of respondents thought that the decision to have a child is influenced by studying medicine. Lack of time was the most common factor considered as a barrier for a parent/pregnant medical student with 'sleep deprivation', 'tiredness', the 'need for extra work and studying in free time' and 'reduced time available to spend with family' all mentioned. Financial difficulty, both during medical school and in the early stages of a career, was the second most common barrier. Medicine is an expensive subject to study, leaving many students and their families in debt. There is no income during the lengthy course and if students work part-time there is added pressure of work-study-family balance. One student commented:'There are financial implications of lengthening the course if the student takes time off.' The NUS review similarly showed that parent students face considerable financial pressures due to a combination of insufficient childcare funding, lack of financial support for associated course costs and reduced benefits. ${ }^{6}$ The nature of studying medicine and the associated pressures was the third most common factor. Many students commented that studying and practising medicine is stressful, demanding and involves hard work, out-ofhours activities and numerous assessments. For these reasons, starting a family is an extra burden that can have a negative effect on their career path. Social factors were considered the fourth most important factor by our respondents. Some students found it difficult to strike a balance between academic and social life and believe that the medical profession leads to an 'antisocial' and 'unstable' lifestyle, with 'lots of time away from home'. 
One important concern was that having children may lead to the alienation of parent students from their peers as they are not able to share in all of the same activities. This is supported by the findings of the NUS review: lack of time, costs, no money for additional childcare, shortage of child-friendly activities and parenting responsibilities were identified as barriers for student parents getting involved with student life and one in ten said they felt isolated. ${ }^{6}$

There were other common themes in the questionnaire responses. Emotional difficulties, stress and psychological exhaustion were particularly highlighted. 'Feeling of guilt as a result of being unable to give the child enough time and attention' and 'pressures of trying to be a good parent and a good student/doctor at the same time' are some of the important stressors. Childcare and the welfare of the child, especially with the introduction of shift patterns, are a particular concern. One student pointed out: 'Being a medical student is not 9-5, while childcare is.' Family support is an important factor for pregnant/parent students. Arhin et al. studied eight pregnant/parent nursing students and concluded that keeping up with assignments, readings and clinical responsibilities was difficult and family support was a pivotal factor in helping students cope. ${ }^{8}$ The NUS review showed that UK students with children face a number of difficulties accessing suitable childcare due to a combination of a national shortage of childcare places, high costs and a shortfall in childcare funding. Students are not considered as 'good customers' for childcare providers due to their irregular hours of work, lastminute changes and the late provision of timetables. As a result, $79 \%$ of student parents in their study frequently or sometimes used family or friends for childcare; of those, $37 \%$ used it exclusively. ${ }^{6}$

The dispersed nature of medical training adds to parent students' problems. While rotation through different hospitals provides excellent training opportunities, travelling large geographical distances is time-consuming, expensive and leads to restrictions on levels of participation in wider student life and a transient knowledge of the support available in each placement. Hospital accommodation may not be suitable, is not always available and arranging childcare at different placements is not easy.

Female students feel particularly under pressure from the burdens of raising a family. Many believed that taking time out may jeopardise their career prospects and that becoming pregnant results in suspicion of a lack of commitment to medicine and loss of respect from tutors. Many feel they have to choose between their career and parenthood. This pressure is compounded by practical concerns about the ability to breastfeed and diminishing fertility with age. Some female students consider putting off medical school in order to have children: 'I feel it's either one or the other', and 'as a woman, you have to get your training out of the way first.' Research suggests that the majority of student parents are women and considered mature students. ${ }^{6}$ Kelner et al. showed that having children was an extra source of strain for female interns or residents who were concerned with providing adequate childcare.? Cujec et al. found that female medical students and residents were less likely than men to recommend parenting to their peers. ${ }^{10}$

Three important issues were repeatedly highlighted. Firstly, despite UK employment laws, it is a cause for concern that fear of being disadvantaged in job applications and being discriminated against in interviews remains a concern for medical students. Second, a lack of support and negative attitude from medical school representatives was also mentioned several times: '[Students are] unable to have a child due to fear of lack of support from the medical school having seen what others have gone through.' 'You sort of have to or even expected to hold off having children.' '[There is] little support and flexibility from medical school regarding placements.' 'Flexibility to continue the course part-time is not available like other non-vocational courses.' Third, it is of concern that almost $90 \%$ of the students who responded to our questionnaire were not aware of the support available for pregnant students/parents.

Our study also showed that studying medicine has implications on other aspects of life, such as the decision to marry, the choice of partner, the number of children they plan to have (usually one or two rather than a large family), and the choice of specialty (some parent doctors felt that 'having a child may restrict career choices' and they tend to choose specialties with less on-calls and weekend hours even if this was not necessarily their preferred specialty). Unplanned pregnancy is a particularly difficult issue and being a student may influence the decision to terminate a pregnancy. On the other hand, a number of participants acknowledged that with certain compromises, it is possible to fit parenthood around a medical career and that there are positive aspects of combining pregnancy/parenthood and studying medicine: 'It makes you more career-focused', 'being a parent makes you more mature, better at time management, able to relate to patients better and more caring.' In a study by Tyden, Swedish female students reported positive views of future motherhood and their concern was mainly about timing." In Kelner's study, participants stated that marriage serves to reduce work stress. ${ }^{9}$

\section{OUR RECOMMENDATIONS}

Medical school programmes should be flexible in accommodating the increased challenges created by pregnancy and parenthood, including more flexibility on clinical placements and the opportunity to suspend 
studies in circumstances such as pregnancy and in cases of family difficulties. ${ }^{2}$ Faculty support is important in helping these students to cope with the additional pressures. Appropriate and easily accessible support services with trained staff should be available to meet the needs of these students. Psychological and academic counselling services specific to parent/pregnant students should also be provided. All students, parents and nonparents, should be informed about these available support systems. Information about financial entitlements for students with children, e.g. childcare funding, should also be more easily accessible. Sufficient and affordable childcare facilities should be provided. Data should be collected on the numbers of student parents in order to ensure a more accurate allocation of resources.

\section{CONCLUSION}

The impact of pregnancy, childbirth and parenthood on studying medicine is undoubtedly significant. Medical students are often faced with stressors such as high work demands, numerous assessments, placements and career choices. Any psychological morbidity that they experience is liable to be exacerbated by the responsibilities of raising a child, leading to ongoing challenges. Student parents are an at-risk group in terms of academic attrition, exam failure and student retention. ${ }^{6}$ This is an under-researched area particularly considering the growing number of mature and second-career students who are enrolling in medicine. Pregnancy and parenting are issues that medical schools will be dealing with on a more regular and growing basis. In addition, recent substantial increases in university tuition fees will put added pressure on these students and their families. Additional or specialised support should be provided to meet the needs of parent medical students to ensure their full and successful participation in learning. We should all work together to change the perception that '[Medicine is a] course designed for single people without family commitments.'

\section{Acknowledgements}

We would like to thank Professor Jonathan Bennett, Associate Dean for Students at Hull York Medical School for his valuable contribution to this study.

\section{REFERENCES}

I Guthrie EA, Black D, Shaw CM et al. Embarking upon a medical career: psychological morbidity in first year medical students. Med Educ 1995; 29:337-4I. http://dx.doi.org/I0.I I I I/j.I365-2923.1995. tb00022.x

2 Firth J. Levels and sources of stress in medical students. $\mathrm{Br}$ Med J 1986; 292: I I77-80. http://dx.doi.org/ I0.I I 36/bmj.292.6529.I I77

3 Malik S. Students, tutors and relationships: the ingredients of a successful student support scheme. Med Educ 2000; 34:635-4I. http://dx.doi.org/I0.I046/j.I365-2923.2000.0054I.x

4 Biggs RL, Douglas BH, O'Boyle AL et al. The impact of pregnancy on the individual and military organization: a postpartum active duty survey. Mil Med 2009; I74:6I-75.

5 Statistics Sweden. [How many children will I have? Fertility in a life-perspective]. Demographic Reports 2002; 5.

6 National Union of Students. Meet the parents: the experience of students with children in further and higher education [Internet]. London: NUS; 2009 [cited 2012 May II]. Available from: http:// www.nus.org.uk/PageFiles/5386/NUS_SP_report_web.pdf

7 Keller S, Collins VB, Jones $\mathrm{W}$ et al. Nursing education barriers identification survey [Internet]. Mississippi: Office of Nursing Workforce; 2003 [cited 2012 May I I]. Available from: http://www. monw.org/publications/2002\%20Nursing\%20Education $\% 20$ Barriers\%20ldentification\%20Survey.pdf

8 Arhin AO, Cormier E. Factors influencing decision-making regarding contraception and pregnancy among nursing students. Nurse Educ Today 2008; 28:210-7. http://dx.doi.org/10.1016/j. nedt.2007.03.013

9 Kelner M, Rosenthal C. Postgraduate medical training, stress, and marriage. Can J Psychiatry 1986; 31:22-4.

10 Cujec B, Oancia T, Bohm C et al. Career and parenting satisfaction among medical students, residents and physician teachers at a Canadian medical school. CMAJ 2000; 162:637-40.

II Tyden T, Svanberg AS, Karlstrom PO et al. Female university students' attitudes to future motherhood and their understanding about fertility. Eur J Contracept Reprod Health Care 2006; I I:I8I-9. http://dx.doi.org//0.1080//3625/80600557803

12 British Medical Association (BMA). Medicine in the 21 st century. Standards for undergraduate medical education in the new millennium [Internet]. London: BMA; 2006 [cited 2012 May II]. Available from: http://www.bma.org.uk/Archive/med2 I st.jsp

I3 Bryman A. Social research methods. 3rd ed. Oxford: Oxford University Press; 2008. 